\title{
Information Technology: My Perspective
}

\author{
Ted Hutchin, Engineering Industry Training Board, East Midlands
}

With the formation of the Association of Inform ation Technology (AIT) the opportunity to see the role of IT gain in prominence and understanding is not to be missed. My work is primarily concerned with the engineering industry through the Engineering Industry Training Board, having joined the Board from the computer industry and before that the Royal Electrical and Mechanical Engineers where I was a radar engineer. In particular I am involved with the way in which companies come to terms with new technology. Engineering companies are turning to IT at all levels in order to remain competitive. Through the presentation of courses, seminars, workshops and work directly in-company, it is hoped that the expertise within companies will become more effective. This is particularly important in those small- to mediumsized companies that have never considered the importance of IT before. As companies consider their IT needs it is crucial that they approach the subject in a clear and systematic manner. Too many companies have pressed ahead and have failed to achieve anything like the benefits they were expecting. Even those organizations that manage to purchase the right software and hardware still come up against severe managerial and organizational problems as a result of not taking account of the 'human factors' that are involved. It is this aspect that I feel presents the greatest challenge to the successful implementation of IT.

There are many barriers to organizational devel. opment with IT implications. These can be seen in the resistance to change, the fear that is associated with new technology, and the inability of many organizations to cost the benefits and risks of implementing IT with any degree of accuracy. There is also an over-dependence on the intangible benefits that may or may not be achieved rather than carrying out a full and thorough study of the organization and its needs. It is my belief that if those who are involved with the IT industry do not assist those who wish to utilize the technology, then there will be no major break through in its use.

If this is the case then the AIT must become much more than just an academic talking shop. What is needed in this country is an independent source of information and advice where companies can come and ask questions about their own business without feeling that they are being sold something. My own area of engineering companies shows that many of them, because they do not understand the technology, are afraid to show their ignorance and then fail to ask the relevant questions if they ask at all. In this journal there should be the opportunity to develop some of the themes that are presented at the Association meetings throughout the year and this could become, in itself, a vital function of the Association.

Certainly my own research at Leicester Poly technic shows that many organizations set about choosing and implementing such technology in a very haphazard fashion. Managers are faced with almost impossible situations in which to choose IT and are rarely equipped to do so. The role of the consultant is one which has caused concern in the past with their close association with suppliers, though this is now being overcome through some of the national agencies such as microsystems centres.

To sum up, I feel that the AIT has a relevant role to play in information dissemination and the creation of informed debate but, much more than that, I feel that it should also be proactive in bringing the whole IT debate to a wider audience of potential users to show what IT can and cannot do, to bring IT into the market place, not as some mythical jargon-ridden subject for academics but one which has relevance to organizations, and their managers, of all types and sizes. 